\title{
INTEGRATING DIGITAL DOCUMENTATION AND COMMUNITY ENGAGEMENT: 'UNVEILING THE HIDDEN HAMINA' INTERNATIONAL SUMMER SCHOOL
}

\author{
J. Garcia-Fernandez ${ }^{1 *}$, L. Medeiros ${ }^{2}$ \\ ${ }^{1}$ CIAUD, Faculty of Architecture, University of Lisbon, Portugal - jorgefernandez@ fa.ulisboa.pt \\ ${ }^{2}$ Faculty of Human and Social Sciences, New University of Lisbon, Portugal - lapmedeiros@ fcsh.unl.pt
}

\author{
Commission II, WG II/8
}

KEY WORDS: Education, Training, Cultural Heritage, Documentation, Community Engagement

\begin{abstract}
Currently, non-formal Heritage Education strategies present an immense potential to valorise and protect cultural heritage $(\mathrm{CH})$, while promoting the transmission and production of knowledge. Integrating the potential of technologies in cultural heritage management practices, particularly in the field of 'heritage documentation', presents a way to empower both experts and non-experts with tools to better understand and record $\mathrm{CH}$ assets. It also allows to use research to advance on conservation, and to create and strengthen links between communities and their heritage. To achieve these in a non-formal context, a learning process/path needs to go beyond merely taking the contents out of the classroom; it requires the development of a strategy where students interact directly of the heritage assets, the communities and the institutions during a continuous amount of time, allowing for immersion, meaningful experience, and dialogue.

In 2018, under coordination of the University of Lisbon and Tampere University of Technology, took place the International Summer School 'Unveiling the Hidden Hamina', in Finland. The course was focused on integrating a non-formal academic course on Heritage documentation with a community-centred approach to cultural heritage. Its primary goals were to develop a learning path merging communities and course contents, to tackle current challenges in Heritage documentation, and to solve some current problems identified by local $\mathrm{CH}$ institutions. This paper provides a description of the course program and learning activities, the community engagement strategies, the integrated socio-cultural agenda and the main outcomes obtained by the course.
\end{abstract}

\section{UNVEILING THE HIDDEN HAMINA}

\subsection{Introduction}

The relevance of non-formal education in both human and technological oriented courses, has been well assessed and distinguished as individual and collective competence maker (Fernandez and Fenandez, 2009). Its experimental use has turned into a recurrent practice, while being recognized as lifelong learning (Craciun and Bunoiu, 2019). Summer School Courses represent a new paradigm in non-formal education, because their capacity to promote teamwork, dynamics interactions, a contextualization of the problems to be addressed, and its influence in further research development and later-on career choices (Domingues et al., 2003 and Michaela, et al., 2018).

Preventive preservation of Cultural Heritage $(\mathrm{CH})$, unlike, remedial conservation and restoration, entail a lower economic cost and less aggressive intervention in terms of irrecoverable degradation, loss-of-authenticity, and human errors. Within Preventive preservation, Heritage Education means to empower students with a knowledge and skill to safeguard $\mathrm{CH}$ assets, and to sensitize communities and individuals on the respect of heritage assets.

Documentation of heritage assets is the first step in preserving a site and its memory (Silver, 2019), accurate data representing the shapes, colours, and relation of elements, are essential documents to communicate $\mathrm{CH}$ values, to plan and conduct conservation actions, and to store a fundamental piece of knowledge. On this line, Educating in Cultural Heritage Documentations as a preventive preservation approach, requires the consideration of challenges proposed by its three main components, described below.

First, 'Cultural Heritage' and its intrinsic formative value, need to be integrated/exploited within the educative action. The use of heritage solely as a case study is not enough. The multiple dimension of local heritage (beyond the tangible assets to be documented) are inextricably linked, and their interrelation is what confers the 'true'/comprehensive cultural value. Our appointed challenge is to consider the multiple direct and indirect relationships among the cultural dimensions and integrate them on in the study of heritage documentation.

Second, '(documentation) technologies' and the specific knowledge associated with the appropriate use of techniques and equipment of survey and representation. Since technology is nowadays all around in our daily life, there is a powerful component of internal motivation when conducting a technological initiative, especially within younger generations. Our main challenge here is to exploit the motivational capacity that technologies have, especially for out-of-school experiences,

\footnotetext{
* Corresponding author
} 
and to introduce current questions in term of techniques and data integration.

Third, Communities and particularly the relation of sense-ofbelonging and identity defined by the pair: communities and CH (Garcia-Fernandez, 2014). Integration of communities in $\mathrm{CH}$ initiatives reveal new forms of cultural information (McGill, 2018). Our main challenge in this component is to introduce a more complex narrative to the understanding of heritage, including the linkage between past and present concerns to local heritage resources.

In 2018, University of Lisbon and Tampere University of Technology, coordinated and conducted the International Summer School Unveiling the Hidden Hamina (first edition). Its main purposes were (i) to improve non-formal learning path by setting the dialog between communities, students, cultural context and science; and (ii) to strengthen the links between local community and its' heritage resources. To the socio (educational) - human (cultural+communitarian) challenges, were added the academic (technological) ones. The summer schools aimed to empower students with practical skills and capacities to create a comprehensive documentation of $\mathrm{CH}$ assets using digital and analogic techniques. The course specifically aimed to tackle the following current limitations:

- To re-define the role and contribution of freehand measuring/technical drawing in the documentation process

- To improve integration between laser scanning and photogrammetry data in capture and processing phases

- To provide experiential learning on the use (analysis and interpretation) of digital outputs

\subsection{Seed project: HALILAMA 2017}

In 2016, the School of Architecture of Tampere University of Technology was appointed to conduct the project Haminan linnoituksen rakennusten laserkeilaus ja 3D-mallinnus (HALILAMA), aiming at the 3D digital documentation of the outer surface of 23 main buildings and courtyards in Old Hamina city, Finland. Developed in 2017 in two stages of four months each, this project produced an accurate database of geometric models (Fig. 1) and represented the initial community relationship forming. It was identified a Social movement looking for innovative solutions to protect and promote their culture, willingness to host initiatives coming from the academic world.

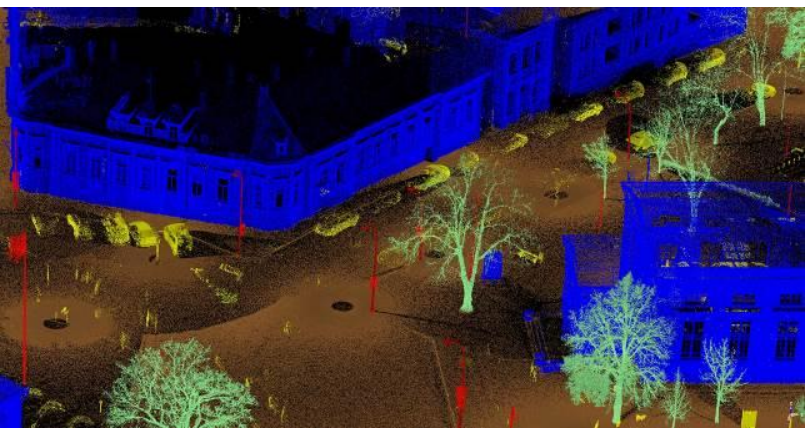

Figure 1. Output from HALILAMA project: classified point cloud

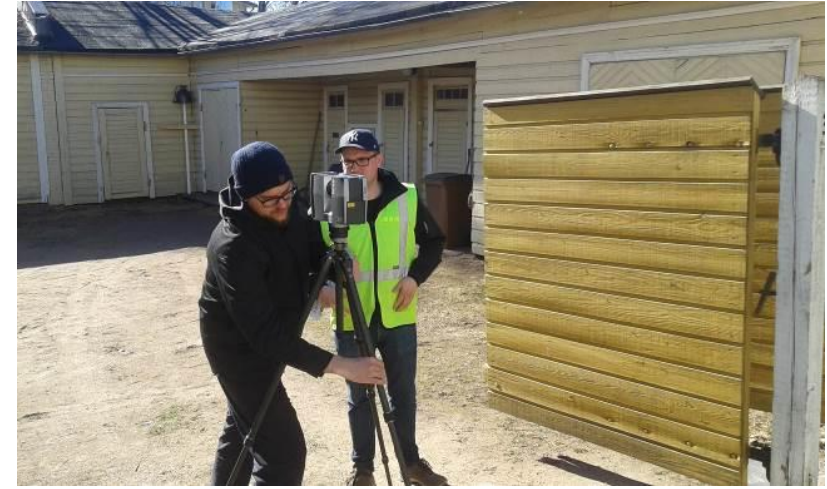

Figure 2. Students conducting a laser scanning training (academic course: Basic of Geospatial Technologies)

The large scope of the project together with a reduced period of work with 'optimal environmental conditions', given the extended winter season in Finland, pushed us to integrate it with an academic training course: Basic of Geospatial Technologies (Fig. 2). The training course together with the student's feedback created also a solid framework where to start developing a summer school on Heritage Documentation in Hamina.

\subsection{Hamina, a unique historical location}

Hamina, (Fredrikshamn in Swedish,) is a singular historical harbour town near the Russian border originally dedicated to King Fredrik of Sweden. Hamina shares identity with its twin city Vyborg, both in the Gulf of Finland (Baltic see). After large periods of war and peace between Sweden and Russia, Vyborg ended up on the Carelian isthmus under Russia governance, while Hamina on the Finnish side (Silver, 2018). Hamina city has been the place of significant historical events such as the meeting between King Gustaf III of Sweden and Empress Catherine II of Russia in 1783 (Nordenstreng, 1909); and has been involved in several military campaigns such as the RussoSwedish War; the Finish War, and the Crimea War.

The military imprint of Hamina is now visible through its current shape, planned by Axel von Löwen and built in early 18 th century. Its ideal circular plan star-like fortress system and singulars intersected encircling and center-radiating streets, echoes the Renaissance urban ideals, achieved only in another place in Europe (Palma Nova, Italy). The city keeps alive its military culture, specially thought the active Garrison and the military academy for officers.

Within the Citadel, the selection of the specific spots in Hamina answers a request from Hamina City, the Association of Old Houses and Courtyards of Hamina Fortress (Haminan linnoituksen wanhat talot ry) and the National Board of Antiquities. These were to study sensitive sites with outdated documentation, and where upcoming development plans will require an accurate geometric documentation. The spot selection also considered specific requirements of the taught contents: relevant areas from the cultural point of views, areas with poor light conditions, and large and inaccessible areas from ground positions.

First, it was selected the Central Bastion of the historical fortress. The Bastion host among other events, the military tattoo Festival of the Finnish Defence Forces, one of the most notable Military music Festival in Europe. Its outdoor Yard is covered in Summertime with the biggest Canopy in Europa and 
is currently the most visited cultural site in Hamina. The other study site were two selected cellars from Historical wooden Houses from the 19th century of the Czars' period. Wooden towns are fire-prone places, and Hamina has suffered recurrent fires, some of them devastating almost $80 \%$ of its extension. Cellars are the remaining structure after fires, and therefore the oldest evidence of the built housing environment.

\subsection{Organization, course statistics and draft from academic syllabus}

The organization focused to integrate all relevant actors: local communities, local government, students, staff and partners in a transversal programme. For providing both expert knowledge and technical updated equipment three Universities joined its efforts: University of Lisbon, Tampere University of Technology, and Tampere University of Applied Sciences and New University of Lisbon.

Providing a bridge between local community and the course, was the Association of Old Houses and Courtyards of Hamina Fortress and City of Hamina. These together with Google Research Data Centre in Hamina, were the main funders of the project. To complement specific knowledges, consultancy and technical solutions, the course integrated relevant partners in the areas of Remote Sensing, Architecture and Cultural Heritage: Agisoft Photoscan, Symetri Addnode Group, Nordic Urbanism Oy, and The International Council on Monuments and Sites (ICOMOS) and the Board of Antiquities, Finland.

The summer school was open to Master students, $\mathrm{PhD}$ students, and early-career PhDs. 15 participant students formed an international cohort from Portugal, Finland, Norway, Sweden, Slovenia, Brazil, Iran, and Pakistan. The course also hosted a wide range of student's backgrounds included architects, archaeologist, $\mathrm{CH}$ managers, historians and Fine Arts. The staff was composed for five professors and four invited speakers, shaping and experiential learning action of 56 hours combing theoric-practical lectures, fieldwork and hands-on training. By the completion of the course, three (3) ECTS Credits were granted by Tampere University of Technology and University of Lisbon.

The course started with a two-days introductory session, conducted in Helsinki, Finland. The location specially took advantage of world-wide known heritage sites related to military heritage and Finnish culture. Moreover, its central location allowed us to bring relevant speakers to the sessions and minimize the transportation of incoming international students. Field trips and educative guided tours where integrated with open roundtables providing a comprehensive vision of local culture and the understanding of students' motivation and interests. Next, five days of intensive learning took place, conducting learning sessions in Hamina city, integrating academic content (four main packages) with a sociocultural agenda, in order to implement the aimed multidimensional vision.

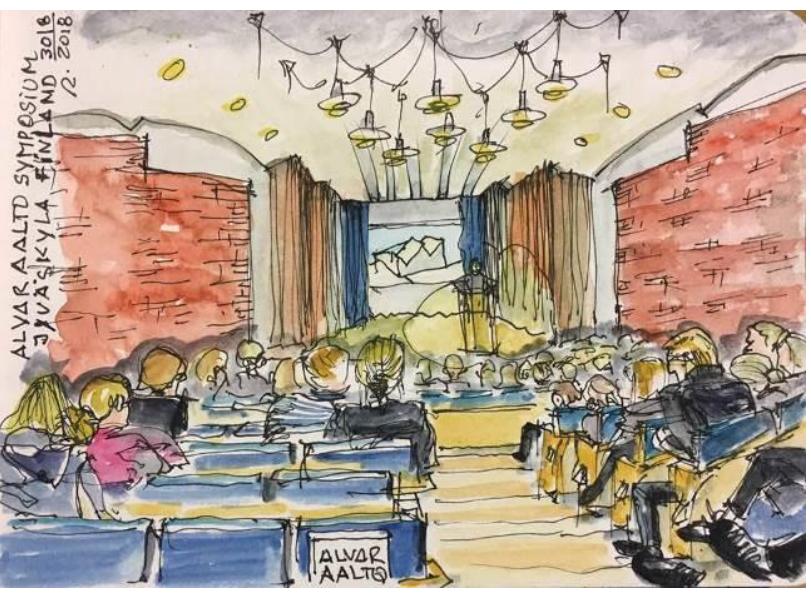

Figure 3. Hand-drawn illustration of Aalto Symposium, provided by student Rui Carvalho

The seven-day course, conducted in the cities of Helsinki and Hamina, was complemented with an optional two-day post course on the $14^{\text {th }}$ International Alvar Aalto Symposium in Jyväskylä, Finland (Fig. 3). This worldwide known triennial event addressing social and technical challenge in architectural context was a unique opportunity for the students to interact with professional and academic, and to expose and debate their gathered experiences. This $14^{\text {th }}$ edition was especially relevant within the course' context because it particularly promoted the integration between construction processes and cultural preferences and variables.

\section{ENGAGING COMMUNITY, A SINGULAR OPPORTUNITY}

Because one primary role of academia is to 'search for answers to our most pressing social, civic, economic, and moral problems' (Boyer, 1996), the conjunction of local stakeholders and academic actors become essential in our educational approach. Since $\mathrm{CH}$ is not only the physical remaining, but a source of individual and community identity (Garcia-Fernandez, 2014), a comprehensive learning on $\mathrm{CH}$ requires the involvement of 'its' community. The study of Cultural Heritage is 'a living experience' and without a living community and context 'it can be (and often is) killed stone dead' (ASE, 2011). Engaging community in the learning process supports also our principle of experiential education, that is a hands-on, active, and in-context education.

In Hamina, we found a community extremely interested in preserving and valorising its culture, and openly willing to support research topic of local importance such as the documentation of their cultural resources. Thought the Association of Old Houses and Courtyards of Hamina Fortress, it was planned and executed a socio-cultural agenda in order to foster student's immersion on local culture and to provide substantial/integral experiences for both community members and participating students

\subsection{Student's immersion through an integrated socio- cultural agenda}

Increasing student's immersion on local culture was one of the main goals of the international school. Looking to enhance student-community interaction, and to bring to the learning process the multidimension of the Cultural Heritage, the course 
had especially designed actions on accommodation, dinner locations, course premises and socio-cultural agenda.

This course showcased a unique diversity of nationalities and cultural backgrounds brought by the students and the local community. Beyond the necessities of cultural acceptance, issues such as religious and political discrepancies can arise specially when students must share accommodation and space for several days. During the first day, a brief student' preparation was conducted, through the promotion of interaction between them in a walking tour and a welcome dinner at the end of the day. Similar solution was conducted for the student-community preparation at the first day in Hamina.

Accommodation was included in the course. Members of the association volunteered to host students, and participants were accommodated in local houses, sharing the place with owners. Premises for dinner and lunch, or to conduct the course's lectures, were also planned to bring the atmosphere of the cultural context to the course. For these were selected the redbrick building of the officers' club, designed by Carl Ludvig Engel (same architect of the Neo-Classical military academy in Finland and the Senate Square in Helsinki), and Linnoitusravintola Kamu! (Fortress Restaurant Kamu!) inside the bastion (Fig. 4).

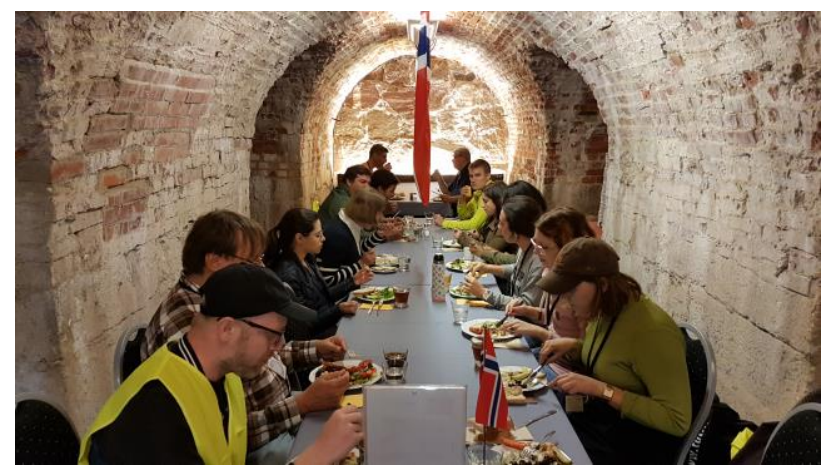

Figure 4. Working lunch inside the bastion at Linnoitusravintola Kamu!

Within the International summer school, it was also designed and implemented an integrated socio-cultural agenda. Each afternoon, at the end of the day, one cultural activity was organized. was specially promoted the complementation of cultural experience in natural heritage (Fig. 6), local traditions (Fig. 7), religion, food, and military-related culture.

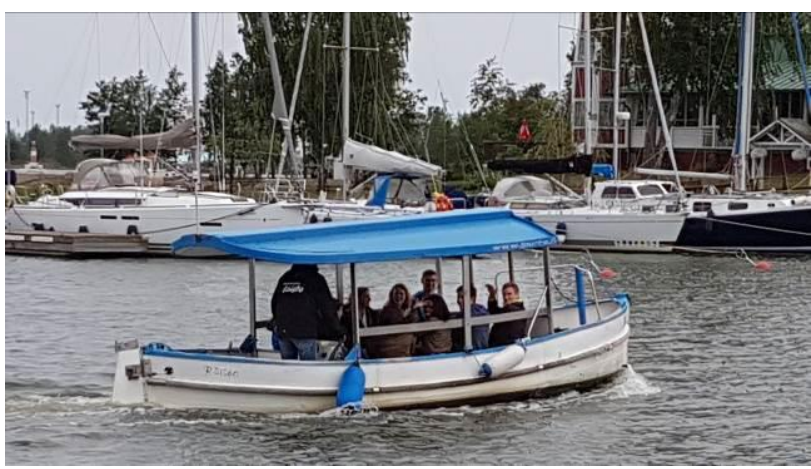

Figure 5. Visit to protected natural heritage site, Eastern Gulf of Finland National Park

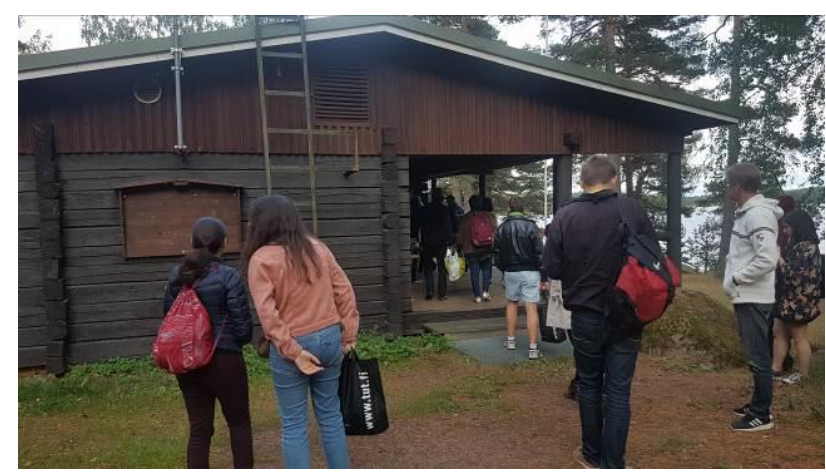

Figure 6. Evening Sauna in the military recreational area of Mäntlahti

\section{COURSE CONTENT}

\subsection{Introduction to military construction in the context of Finland.}

First introductory part of the course looked to introduce the course goals and content and the local culture.

The relations between Hamina and Helsinki, specially in terms of military traditions and cultural resources, prompted us to start this stage in the city of Helsinki. Helsinki's central 1 location allowed us also to bring relevant invited speakers on Finnish culture and $\mathrm{CH}$ documentation, such as Ms. Minna Silver, president of ICOMOS Finland; and vernacular architecture and Heritage preservation such as Professors Fernando Vargas and Camila Mileto (University of Valencia).

Introductory lectures were complemented with a Field trip day to the inhabited sea fortress island of Suomenlinna in Helsinki (Fig. 7). This site, inscribed on the United Nations Educational, Scientific and Cultural Organization (UNESCO) World Heritage List, is one of the best preserved and musealized historical military premise.

It was of special interest the study-visit to the remnants of the $18^{\text {th }}$ century fortress. Its star-like fortification structure following the Vauban's fortification system (Minna, 2018), has similarities in shape and period of construction to Hamina fortress. Educational trip included short talks of relevant scholar such as Prof. Marinos Ioannides from (Cyprus University of Technology), and Prof. Gayle McKeen guiding tour on Finnish Architectural Heritage in Helsinki.

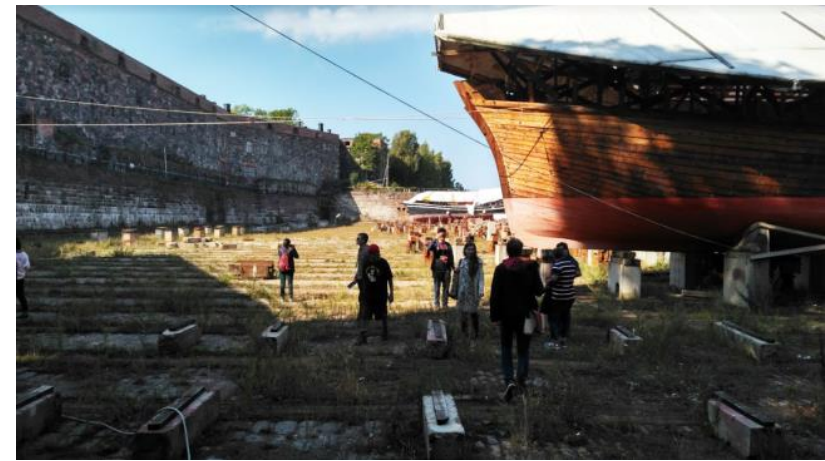

Figure 7. Visit to the 1750's drydocks in Suommenlina (oldest in Finland and one of the oldest operational dry docks in Europe) 
The second day continues with the introduction of the study site, in Hamina. A general vision to the history of the city was conducted by representative of Hamina City. Results of previous documentation tentative in the nearby city of Turku were presented by archaeologist Kari Uotila which opened the debate in the uses of documentation for preventive and physical prevention of heritage. This package ended with the physical visit to the historical town and the heritage spots under study (city walk), conducted by members of the partner association. At the end, it was accomplished a better understanding the role of the city in the Finnish context, and the student's immersion within the cultural spirit of city, fundamental for conducting the next hands-on trainings.

\subsection{Freehand measuring drawings}

There is open debate on the conflicts and current values of hand drawing practice (Dulaney and Lyn, 2010). The affirmation of simultaneous use of digital and analogic techniques is repeatedly supported, however, when it comes to field and documental drawing in $\mathrm{CH}$, much less attention received the need for their optimal integration.

Our thesis supports the need of extracting the capacities of visual and physical interaction that field hand-drawing have. For us, this is especially useful to optimize/increase efficiency in further remote sensing-based documentation, while creating a singular bond between drawer and the site. Moreover, the process of thinking\&drawing in-situ, specially carried on by archaeologists, architects, and conservationists, may have repercussion on further physical preservation decisions. The coordination between the physical presence in drawing and the technical background can shed significant conclusions on structural assessment, materiality and other relevant issues to consider in preservation processes.

This first practical package of the course was conducted by Professor Olli-Paavo Koponen. Students. Students coming from social and human areas receive their first introduction on the use of basic human measures and sketching techniques. Looking to support and improve next phases, this package specifically addressed issues on:

- spatial analysis allowing for increasing expediency/efficiency of remote-sensing survey (in terms of accessibility and lighting conditions)

- physical presence/interaction, increasing the level of understanding of relevant features to be surveyed

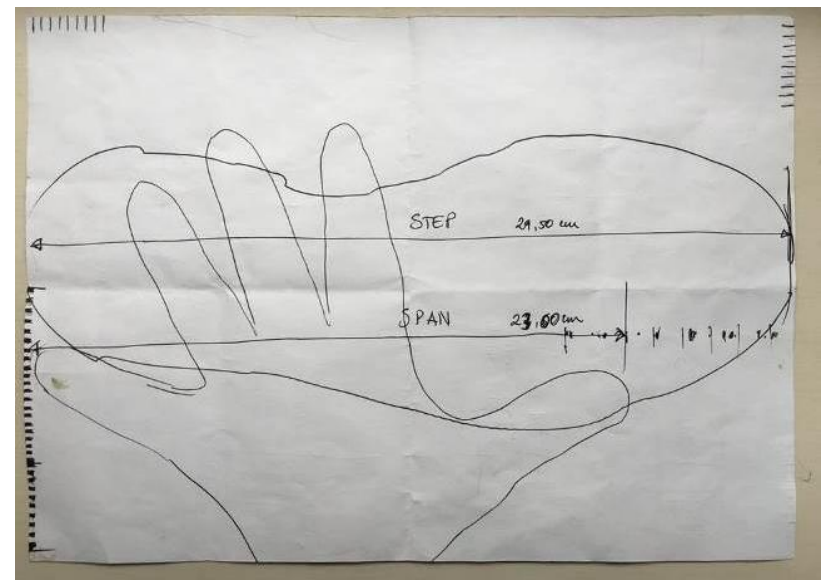

Figure 8 . Understanding of basic human measures, provided by student Rui Carvalho
After this package, students were able to create basic plans and sketched details with proper scale and orientation.

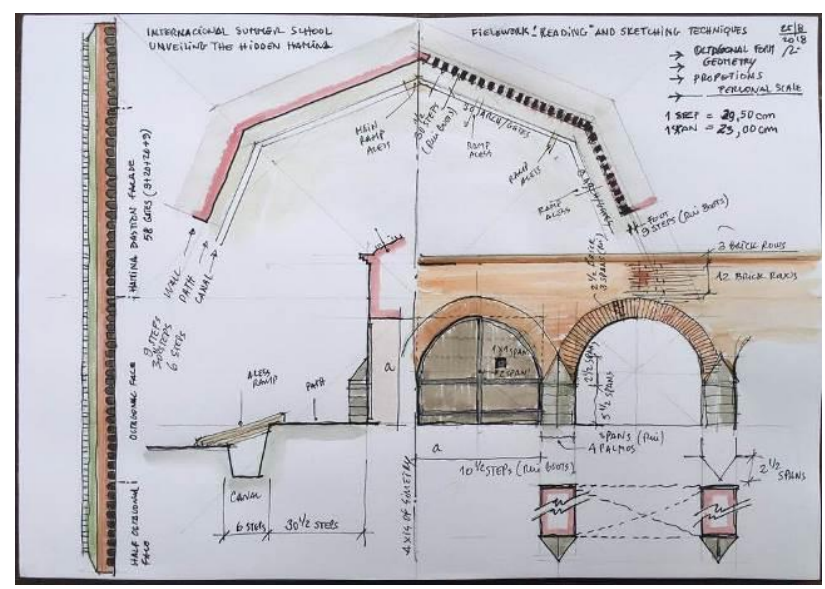

Figure 9. Representation of singular details and its basic measures, provided by student Rui Carvalho

\subsection{Laser Scanning and Aerial Photogrammetry}

Documenting a place is a key starting point for the $\mathrm{CH}$ preservation. Laser Scanning and photogrammetry are two of the main technologies used on current documentation strategies. An increasement in accuracy and resolutions, has been recently balanced with a decrement on equipment cost. The integration of this technologies with GPS survey, enhance data with the capacities to be externally oriented. Having our models in global coordinates, allows the data independence from local references (streets, postal codes. etc.), especially temporary in our ever-evolving cities.

Learning packages of Laser Scanning and Aerial Photogrammetry focused on empower students with expert knowledge for the identification of potentialities and limitations of each technology, and to apply them on real case scenarios. The course also addressed a main challenge, long-faced challenge by both industry and academy (Hoon and Hong, 2019), on the optimal integration of Laser Scanning and Photogrammetric approaches. These two packages proceeded to bring the knowledge acquired in the hand-drawing field documentation, to plan and execute the field-work documentation training.

The spots selection (Bastion and Cellars), as mentioned before, helped to recognise the specific advantages and limitations of both techniques. In Cellars, where the light conditions where extremely poor (no window and no electricity access for artificial illumination), Laser Scanning achieved accurate results with a minimum cost on time and effort. In the bastion, where outer curtain wall and rampart were partially inaccessible from ground positions, aerial photogrammetry affordably recorded the targeted features, including real-colour information to the scene.

Laser Scanning package was conducted by professors Kalle Tammi and Ilkaa Tasanen, and included a half-day management session. At the end of this stage, students were able to clean, decimate, align and extract sub products of the raw point cloud data. 


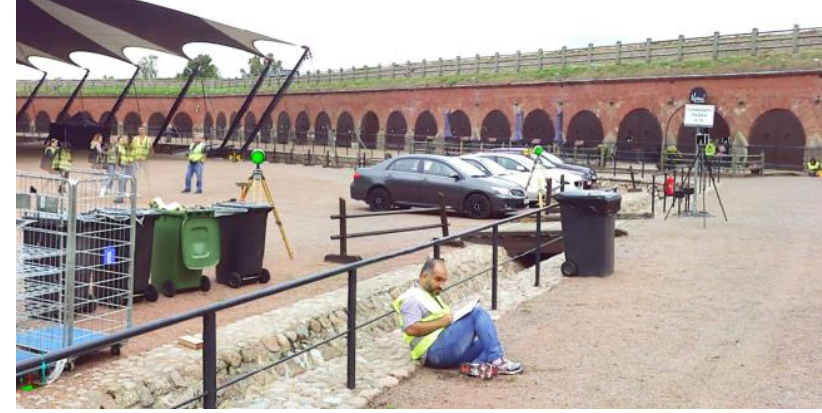

Figure 10. 2D Laser Scanning data image obtained in the training of data processing

Aerial Photogrammertry package was conducted by Jorge Garcia-Fernandez, and assisted by Alexey Pasumansky from Agisoft LLC through a remote connection, covering specific issues on the usage of Agisoft Photoscan (Fig. 11). This package included the integration of both laser scanning and photogrammetry data. The main goal was to develop e comprehensive 3D models, minimizing areas without information, and enhancing the data with real colour information (Fig. 12).

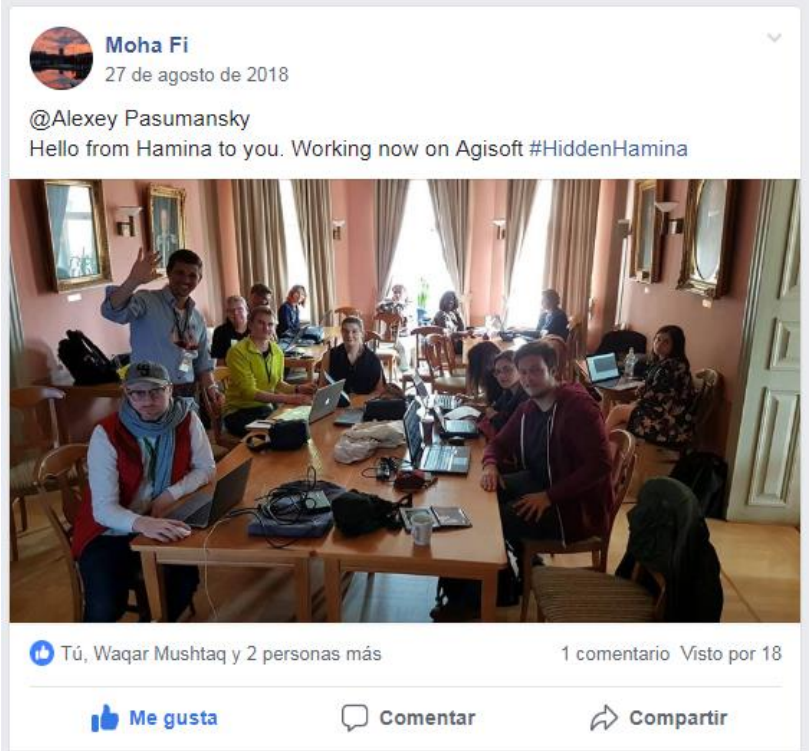

Figure 11. Posted picture on Facebook to our online, posted by student Mohammad Boroojerdi

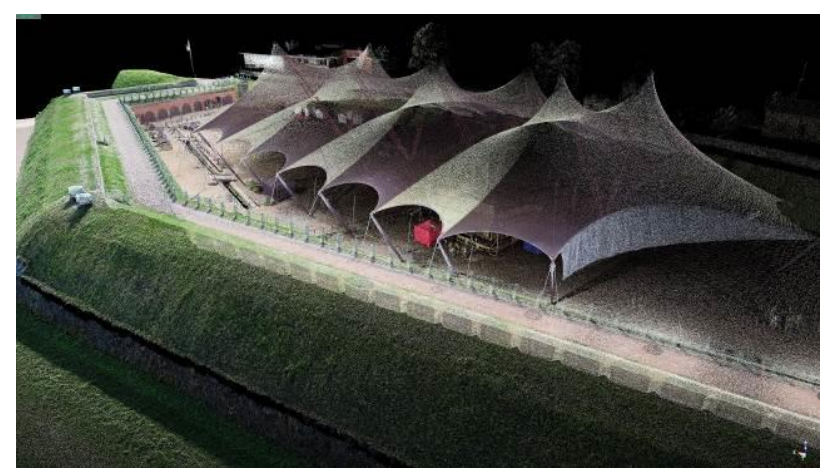

Figure 12. Integration between data, inner bastion and canopy documented with Laser scanner, top and outer bastion documented through Aerial Photometric technique

\subsection{Archaeology of Architecture, an applied used of remote- sensing based documents}

Following the course's goal of exploring various documentation approaches and given its trans-method approach to the results, the students had on their last day of course-work a module on building archaeology. This module again integrated both the theoretical presentation of contents (the context, goals, and methods of the discipline) and the practical experimentation of this approach to the built heritage.

Conducted by archaeologist and professor Leonor Medeiros (NOVA FCSH), the students were introduced to ideas of archaeology, stratigraphy, wear patterns or historical layers, which they then applied to the buildings under analysis. Divided into teams, the students had the opportunity to, in each of the selected sites, delve into and write the story of the building through nothing more than the clues left by the transformations those had suffered through time.

According to best practice, the students used the precision documents (true-ortho images) produced in the previous days (Fig. 13), and contrasted each one with the evidence, taking conclusions about both the potential and the limitations of photogrammetry and laser scanning to show the site's history or to do archaeology of architecture. For example, the scale of detail was discussed, as well as colour fidelity, and especially the ease of measuring or making base-drawings with which to then make the stratigraphic analysis on the field.

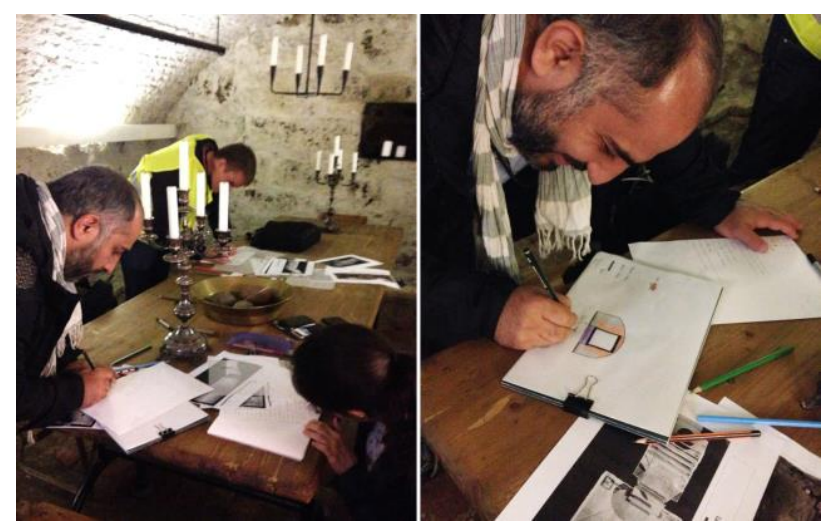

Figure 13. Student conducting stratigraphic analysis in Cellar

The students then proceeded to analyse each of the walls of the building, as well as floor and ceiling in the case of the cellars: attention was paid to the differences in the materials used and how they could indicate adaptations and transformations in the site, small details (nails, imprints of gone electric wire, openings, wear patterns of doors and other objects, etc.) were placed over the base drawings based on the true-ortho images, a colour code was applied, and questions of historic and social nature were made to the evidences gathered.

This organization of information was then used by the students to establish stratigraphic relations of overlapping, filling, sustaining, cutting or joining between different areas and elements of the space, identified as stratigraphic units. By attempting to determine the stratigraphic sequence and place it in its historical context, the students actively engaged in discussions, changing their ideas frequently about what was more ancient or not, succeed in collaborating and dividing work 
tasks, and resulted in new questions they had to ask to the owners and the community, extending the discussion further.

\subsection{Community feedback and result's presentation}

Since the community was, along the course, a keystone to promote the full understanding of the cultural values, it was designed an evening session on social analysis and community engagement. The doors open event|: 'Grab-a-free-pizza-slice community meeting' was conducted by Professors Panu Lehtovuori and Dalia Milian-Bernal. It promoted an open discussion covering the topics of community agency and empowerment, and sustainable use of local cultural resources. It particularly focused at bringing to the spot the role of communities in $\mathrm{CH}$ management, and the use of digital heritage document for the preventive preservation. The session was an opportunity for resident to bring their thoughts on how to preserve and promote their heritage resources. Discussion also covered cultural issues related with tourism, transportation and entertainment.

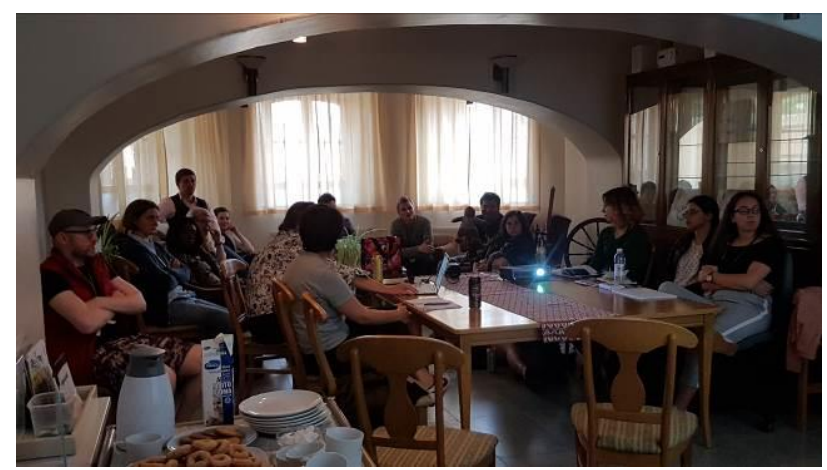

Figure 14. Open Roundtable session with community members, at the officer club

The last-day session was focused on compiling the developed documentation and creating a narrative of the course progresses. With a draft introduction to Storytelling, students were able to create their course's story and engagingly represent the created outputs. Results were presented on an open-public event at Hamina City Hall. Together with students and community, relevant stakeholders took part on the event, including Hamina's Major, representatives of Google, and the member of the Board of Antiquities.

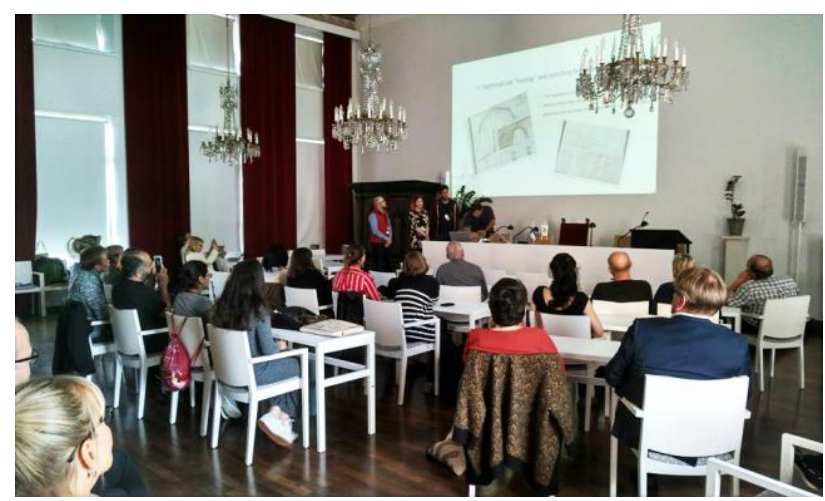

Figure 15. Presentation of results at the Hamina City Hall

\section{DISCUSSION}

Teaching technologies in the context of cultural heritage often marginalize the socio-human components. Communities are an irreplaceable actor when conducting heritage education action, and the opportunity to count on them should be exploited from the very first moment of the action design.

The International Summer School Unveiling the Hidden Hamina, designed a non-formal learning path combining community engagement, cultural heritage and technologies. The course empowered 15 Students with new knowledge and skills, while providing a unique experience for both community members and participating students. Through active engagement with the local community - as was achieved by working to answer local needs or by living under the same roof for several days - a closer connection between all those involved provided experiences that go beyond training in documentation, making it both a cultural and a scientific exchange.

Through the summer school, relevant outputs in form of 2D plans and 3D models were created (Fig. 16). Local government and $\mathrm{CH}$-related institutions in Hamina city were supplied with these documents and post-course reports. Additionally, the course developed a multidisciplinary contact network within participants (students, staff and partners) and promoted the development of new areas of research.

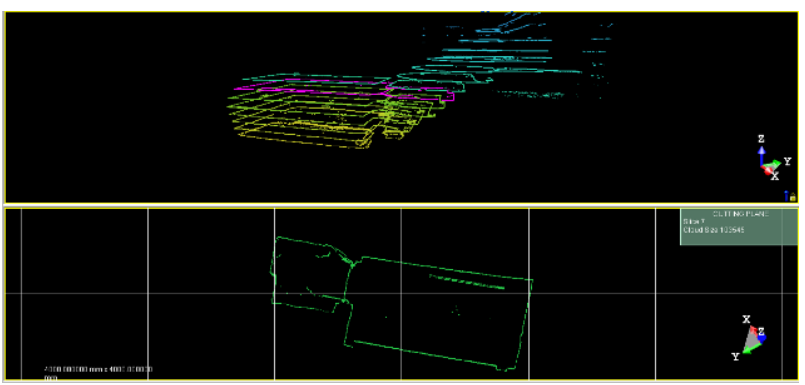

Figure 16. 3D cross-sections and 2D metric maps

Feedback from course evaluations through an open-ended survey, indicates a high rating in the significance of community integration within the course, and the relevance of the proposed contents. It was also positively valued the field-work sessions and real-case analysis. The feedback also pointed out the intense tight schedule and how the students would have liked to have a longer course, namely, to aid in better dominating what was for many an entirely new content, which will require redesign of the course's program for further editions.

Beyond the practical outputs and gained skills, the integration of local perspective (from residents) and academic and technical vision (from professors and students), decisively enriched the collective memory of Hamina. The multiple interactions between students-community and the linkage with local heritage, promoted along the course, created affective bonds (Fig. 17) that are essential for the valorisation and protection of the heritage of Hamina. 


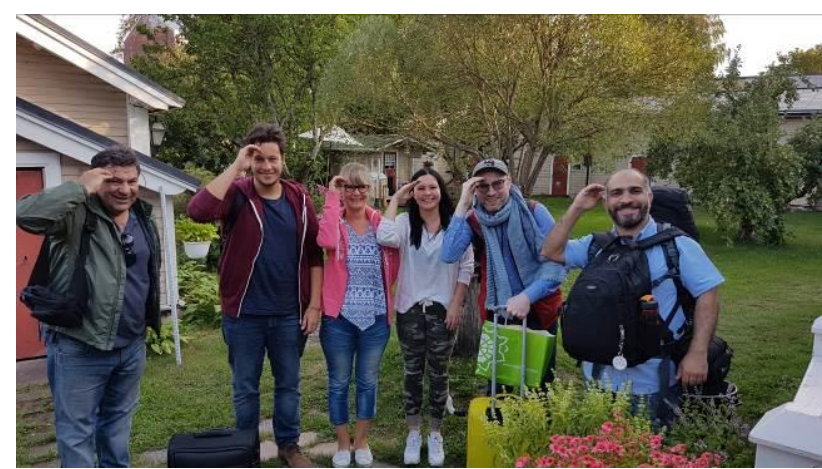

Figure 17. Farewell photo with group of students and their hosts (in the centre), provided by student Mohammad Boroojerdi

\section{ACKNOWLEDGEMENTS}

The research leading to these results has received funding from the Research and Innovation Framework Programme (Marie Curie Actions) of the European Union's Horizon 2020 Framework Programme H2020-MSCA-IF-2016, project no. 747046.

The authors wish to thank all the colleagues and institutions who supported the International Summer School, and specially to the students who enthusiastically contributed to its successful completion.

\section{REFERENCES}

Association for Science Education and Outdoor Science Working Group (ASE), 2011, Outdoor science, Shrewsbury: Field Studies Council and King's College London.

Boyer, L., 1996, The scholarship of engagement., Journal of Public Service and Outreach, 1:1,11-20.

Craciun, D., Bunoiu, M., 2019, Learning science outside the classroom: A summer school experience, AIP Conference Proceedings, 18th Physics Conference, TIM 2018, 2019:2071, Art. No. 050002

Domingues, I., Agreira, C., Valdez, M., 2013, The success of active and cooperative learning in Summer School Courses, Proceedings of the Universities Power Engineering Conference, Art. No. 6714993

Dulaney, R., Lyn, F., 2010, Representational craft and production: Comparison of the value of hand drawing and digital media in architectural academies and practices, Design Principles and Practices, 4:1, Pages 281-290

Fernández, M., and Fernández, S., 2009, The recognition and accreditation of non-formal and informal learning: Historical references, social functions and theoretical perspective, Revista de Educacion, 2009:348,253-281

Garcia-Fernandez, J., 2014, Digital Culture for the Enhancement of Heritage Values, PhD Thesis, Ed. University of Valladolid. p. 567

Hoon, Y.J., and Hong, S., 2019, Three-dimensional digital documentation of cultural heritage site based on the convergence of terrestrial laser scanning and unmanned aerial vehicle photogrammetry, ISPRS International Journal of GeoInformation, 8:2, art. no. 53

McGill, A., 2018, Learning from cultural engagements in community-based heritage scholarship, International Journal of Heritage Studies, 24:10, 1068-1083

Michaela, M., Franz B., and Sofoklis, S., 2018, Professional Development in Science Summer Schools: How Science Motivation and Technology Interest Link in with Innovative Educational Pathways, International Journal of Learning, Teaching and Educational Research, 17:5, 47-63

Nordenstreng, S, 1909. Fredrikshamn: såsom befast gränsort och stapelstad 1721-811. Akademisk Afhandling. Vasa: F.W. Unggrens boktryckeri.

Silver, M., 2018, Preserving a place, conserving memory: Recording and documenting in the digital era, CIPA Newsletter 16, digital edition. 